$\operatorname{Minn} .3 .3$

\# 354

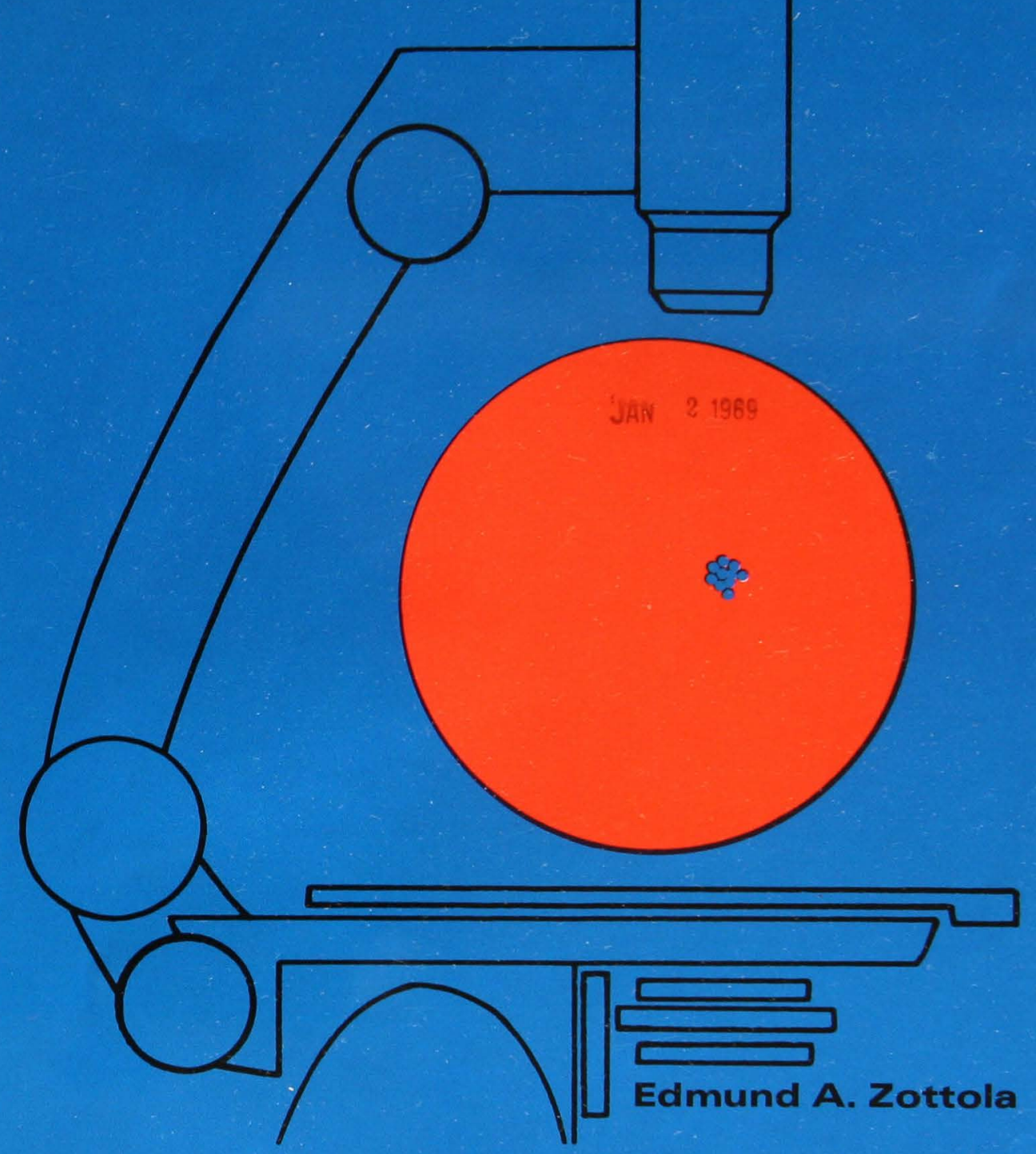

staphylococcus food poisoning

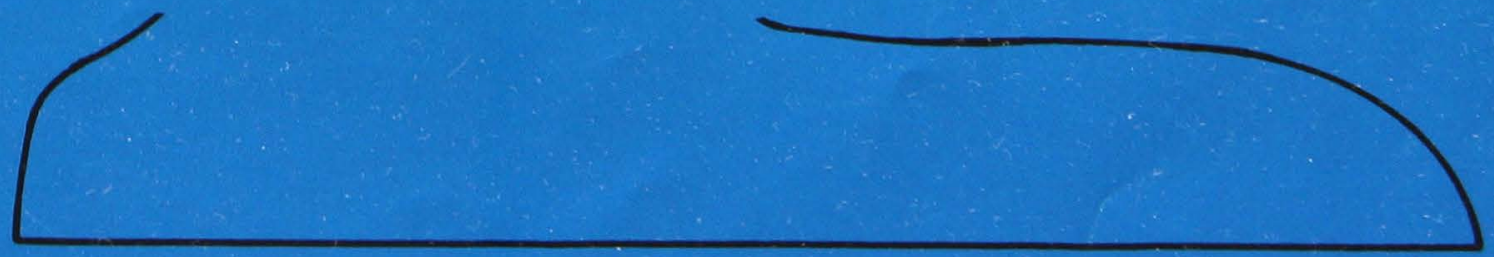

agricultural extension service university of minnesota 



\section{staphylococcus food poisoning}

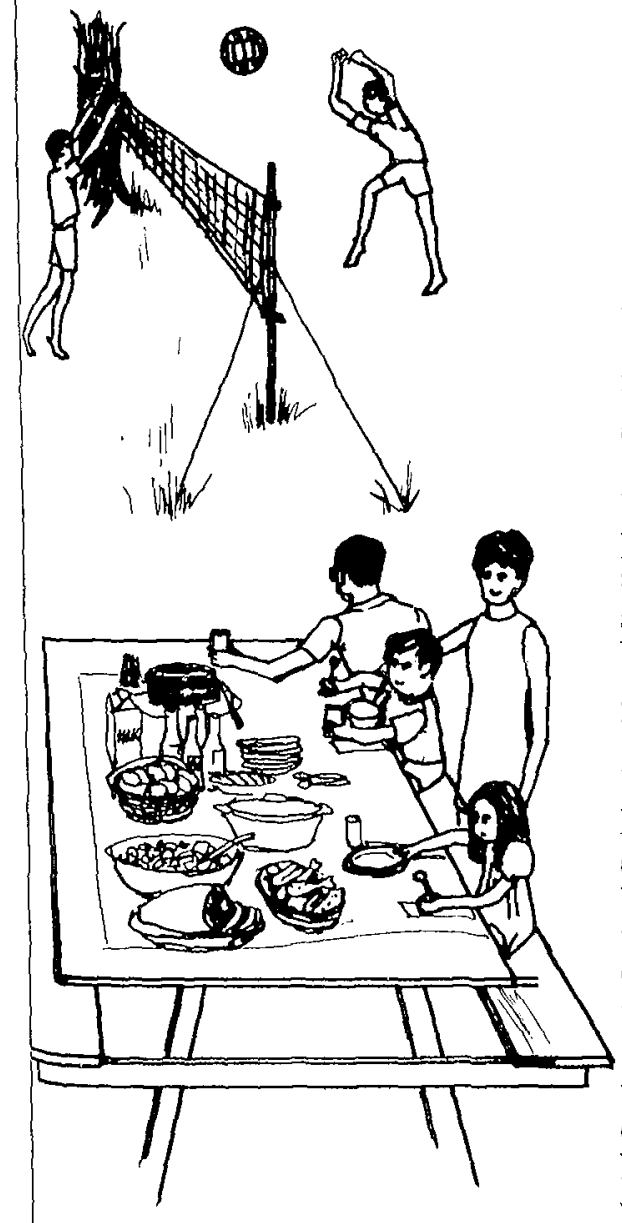

It was a beautiful day for a picnic. The sun was shining brightly and a fluffy cloud or two floated gently across the sky. The 250 employees of the $\mathrm{ABC}$ Manufacturing Company and their families. were looking forward to a delightful time at the company's annual picnic. But their good time didn't last long! Three or 4 hours after they had eaten a picnic meal prepared by a local caterer, many of the picnickers fell ill. The most common symptoms were nausea, diarrhea, vomiting, retching, and stomach cramps. In some cases hospitalization was required. What had happened? Why did this enjoyable outing result in misfortune? These picnickers were victims of the most common form of food-borne disease affecting man today - STAPHYLOCOCCUS INTOXICATION.

Why did so many of these people get sick? To determine why, it's necessary to examine not only the food they ate but also how it was prepared. The picnic meal consisted of ham, fried chicken, potato salad, baked beans, rolls, pickles and other relishes, coffee, milk, soda pop, and chocolate cake and ice cream. Bacteriological examination of leftover food obtained from the caterer showed that the ham and potato salad both contained the microorganism, Staphylococcus aureus. Of these, the ham showed the greatest degree of contamination.

To determine how the food was contaminated, the way it had been prepared was investigated. The ham had been baked the night before the picnic. Early the next morning, an employee of the catering service sliced and placed the ham in a warm, but not hot, oven. It was determined that several employees had eaten some of the ham when it was sliced and none had fallen ill. Further investigation revealed that the employee who had sliced the ham had an infected cut on the palm of his hand with which he had handled most of the sliced ham. Bacteriological examination of the infected cut revealed Staphylococcus aureus. Apparently the infected cut provided the source of contamination, and a suitable environment for growth of the bacteria was provided by placing the ham in a warm oven until it was served. The potato salad had also been contaminated by this employee. But since the salad was refrigerated until consumed, the bacteria did not grow, and this food probably was not an additional source. of the food poisoning.

Had the caterer taken a few simple precautions, this enjoyable picnic would not have become a nasty experience. The employee with the infected cut on his hand shouldn't have been allowed to handle the food or should have been required to wear clean plastic or rubber gloves while working with food. The sliced ham should have been kept hot (at a temperature above $140^{\circ} \mathrm{F}$.) or cold (below $45^{\circ} \mathrm{F}$.) until served. Storing the ham at either temperature would have prevented growth of the staphylococcus organisms and eliminated the outbreak of food-borne intoxication. 


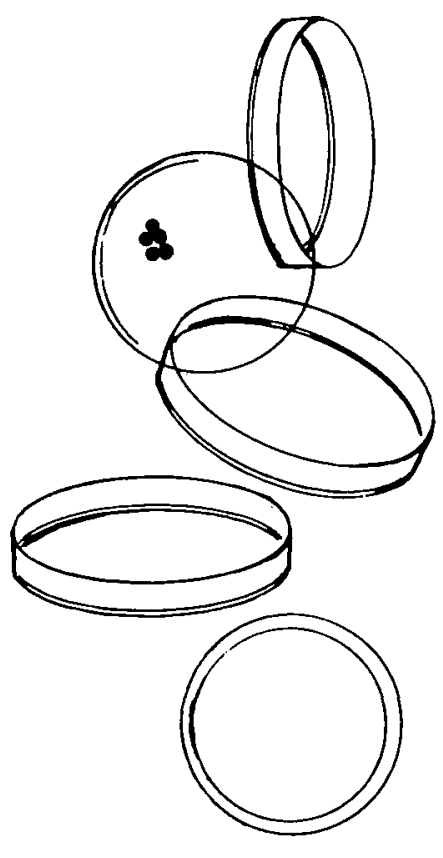

\section{"Poisoning" by Bacteria}

The term "food poisoning" is commonly used to encompass all types of illnesses caused by food-borne microorganisms. Acutally, there are two general types of bacterial food-borne illness. The true food poisoning or food intoxication is caused by eating food that contains a toxin or poison present as a result of bacterial growth in the food. Staphylococcus food poisoning is this type.

The second type is referred to as a food-borne infection or food infection, an illness caused by eating food that contains certain types of bacteria which may or may not have grown in the food. Once these organisms are in the body system, growth and illness can result. Salmonellosis is a good example of a food-borne infection.

Staphylococcus intoxication or food poisoning is probably the commonest form of food-borne diseases affecting man today $(2,4)$. The actual number of outbreaks occurring each year is difficult to determine since the majority of the cases go unreported. The symptoms appear within 2 to 4 hours after eating contaminated food and are characterized by diarrhea, vomiting, prostration, and abdominal cramps. Recovery is complete within 24-48 hours. Usually, a physician is not called and most afflicted individuals will be satisfied with the diagnosis of food poisoning or as it is often incorrectly called "ptomaine" poisoning."

An outbreak of food-borne staphylococcus intoxication may involve large groups of people when it occurs at banquets, picnics, or public institutions. When this happens publicity results and action is taken to determine the cause of the illness. However, a great many outbreaks may involve only a few people and be confined to one or two individuals in a family. In such instances no attempt is made to determine the cause, and quite often the illness is disregarded as "stomach flu" or a "virus" and forgotten in a short time. Consequently, it is very difficult. to document and define the cause of the sickness.

Outbreaks of food-borne staphylococcus intoxication occur as the result of eating foods that contain a poison produced by the bacteria, Staphylococcus aureus, growing in the food. This poison is called enterotoxin because it causes inflammation and irritation of the lining of the stomach and intestinal tract. In order for the illness to occur four conditions are necessary:

\footnotetext{
1 "Ptomaine" poisoning - The term ptomaine poisoning is incorrectly applied to many outbreaks of food-borne illness. The word ptomaine refers to toxic amines that have been formed as the result of protein decomposition and was first applied to food poisoning in 1889 . Outbreaks of food-borne disease are usually associated with food that appears sound and unspoilect. In order for food to have ptomaines or toxic amines present, decomposition of the food would have to occur to such an extent that the food would be unfit for consumption. Although it has been demonstrated many times that outbreaks of food-borne disease are caused by microorganisms, the term ptomaine poisoning is still incorrectly used to describe the illness (10).
} 

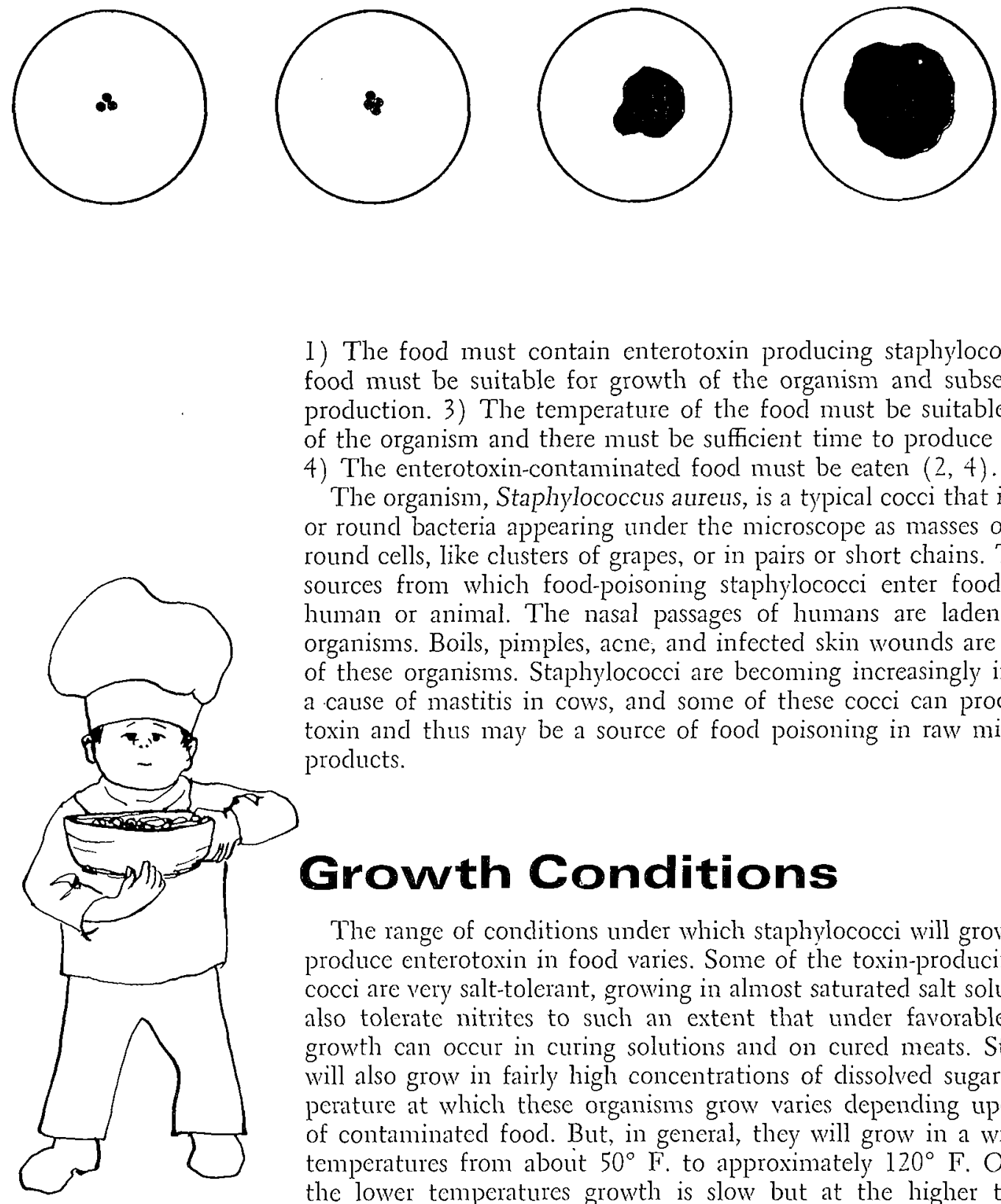

1) The food must contain enterotoxin producing staphylococci. 2) The food must be suitable for growth of the organism and subsequent toxin production. 3) The temperature of the food must be suitable for growth of the organism and there must be sufficient time to produce enterotoxin. 4) The enterotoxin-contaminated food must be eaten $(2,4)$.

The organism, Staphylococcus aureus, is a typical cocci that is a spherical or round bacteria appearing under the microscope as masses or clusters of round cells, like clusters of grapes, or in pairs or short chains. The primary sources from which food-poisoning staphylococci enter foods are either human or animal. The nasal passages of humans are laden with these organisms. Boils, pimples, acne, and infected skin wounds are also sources of these organisms. Staphylococci are becoming increasingly important as a cause of mastitis in cows, and some of these cocci can produce enterotoxin and thus may be a source of food poisoning in raw milk and milk products.

\section{Growth Conditions}

The range of conditions under which staphylococci will grow and hence produce enterotoxin in food varies. Some of the toxin-producing staphylococci are very salt-tolerant, growing in almost saturated salt solutions. They also tolerate nitrites to such an extent that under favorable conditions growth can occur in curing solutions and on cured meats. Staphylococci will also grow in fairly high concentrations of dissolved sugars. The temperature at which these organisms grow varies depending upon the type of contaminated food. But, in general, they will grow in a wide range of temperatures from about $50^{\circ} \mathrm{F}$. to approximately $120^{\circ} \mathrm{F}$. Of course, at the lower temperatures growth is slow but at the higher temperatures growth is very rapid. It should be pointed out and emphasized that when growing in food these organisms produce no obnoxious odors, nor is the appearance or flavor of the food altered in any way. Thus it is almost impossible to sense the presence of staphylococci or entertoxin by the appearance of the food (4). 


\section{Foods Frequently Contaminated}

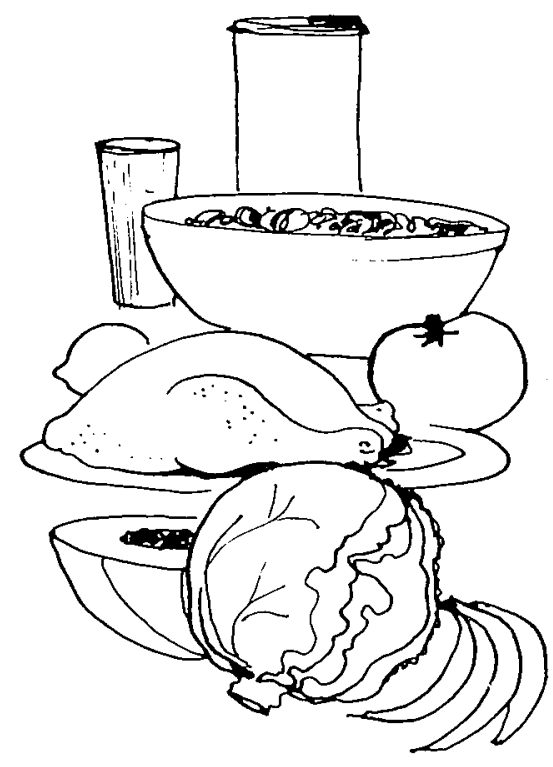

There are many types of food in which staphylococci can produce enterotoxin. Some of the food commonly involved in outbreaks of foodborne staphylococcus intoxication would include the following: $(1,4)$.

1. Meat and meat products such as ham or other prepared meats.

2. Poultry and egg products, chickens, turkeys, custards, eggnogs.

3. Prepared salads such as egg salad, tuna salad, potato salad, chicken salad.

4. Baked goods such as creme filled pastries, creme pies, chocolate eclairs.

5. Sandwich fillings such as egg, tuna, or ham.

6. Raw milk and milk products.

7. Prepared dishes such as casseroles and baked beans.

Any food requiring a great deal of hand labor in preparation is a possible source of staphylococcus food poisoning, particularly if the food has been mishandled after preparation.

\section{Factors Causing IIIness}

Usually when an outbreak of staphylococcus food poisoning occurs, not all individuals who have eaten the contaminated food fall ill. Why is this the case? Inclividuals vary in their susceptibility to the action of the toxin. The amount required to make one individual sick may not affect a second person, whereas this same concentration of toxin may make another individual quite ill. In an outbreak it is possible to have varying degrees of illness in different individuals - all of whom have eaten the same amount of contaminated food. The incubation period (time between consumption of the contaminated food and appearance of the first symptoms) for this type of food poisoning is usually 2 to 3 hours, thus differing from other common types of food-borne infections, such as salmonellosis, which usually has a longer incubation period. The symptoms persist until the toxin is removed from the system, but recovery in most cases is complete within 24 hours. For the most part, no treatment is given except in extreme cases when saline solutions may be given to restore the salt balance and counteract dehydration. Death from this illness is extremely rare (4). 

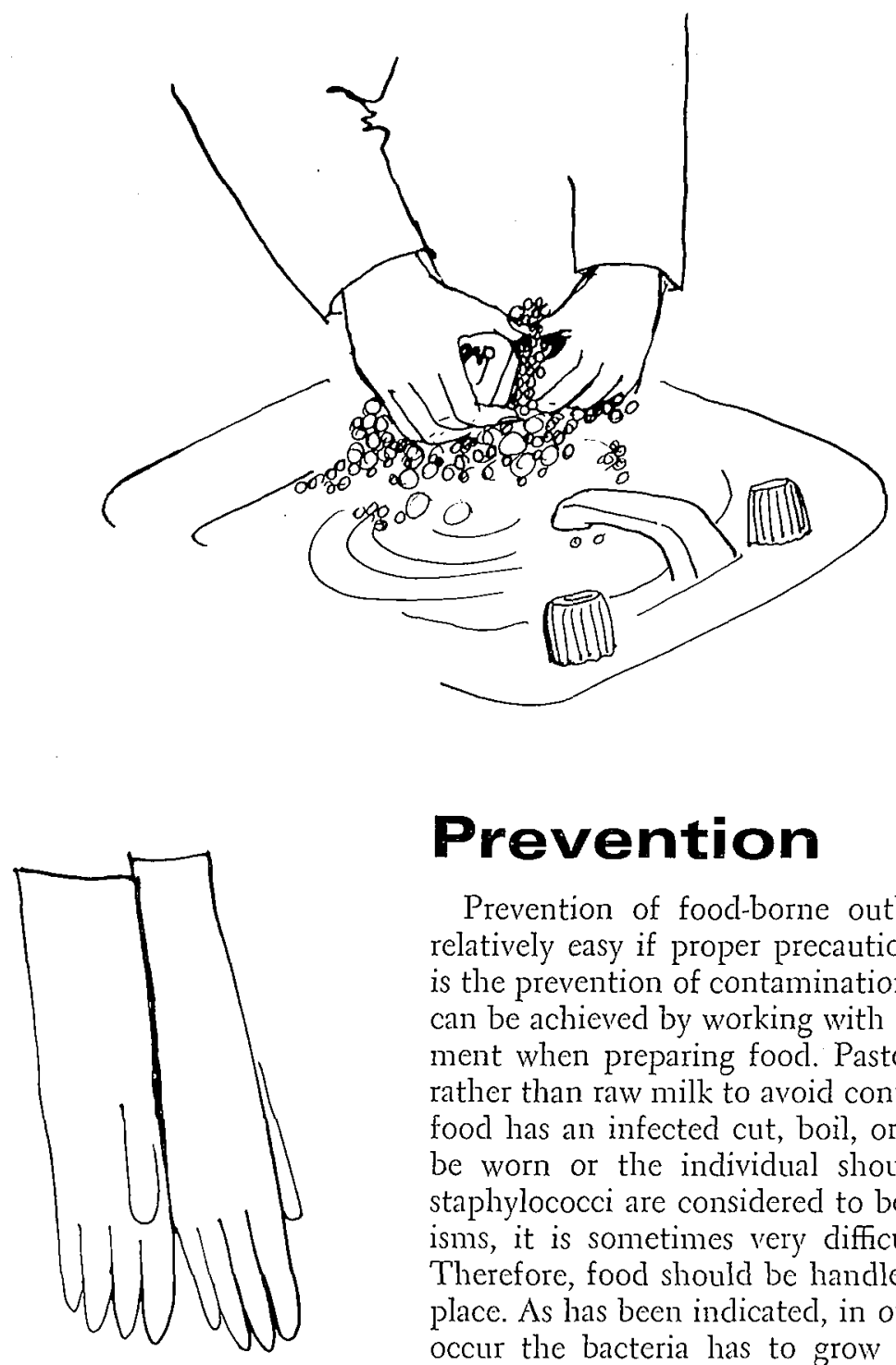

\section{Prevention}

Prevention of food-borne outbreaks of staphylococcus intoxication is relatively easy if proper precautions are taken. The most obvious method is the prevention of contamination of the food with the staphylococci. This can be achieved by working with clean hands and clean and sanitary equipment when preparing food. Pasteurized milk is staphylococci-free. Use it rather than raw milk to avoid contamination. If an individual working with food has an infected cut, boil, or other skin irritation, then gloves should be worn or the individual shouldn't handle the food. However, since staphylococci are considered to be ubiquitous (present everywhere) organisms, it is sometimes very difficult to prevent their entrance into food. Therefore, food should be handled so no growth of these organisms takes place. As has been indicated, in order for staphylococcus food poisoning to occur the bacteria has to grow to produce the toxin. One of the best methods available to food handlers to prevent growth of these organisms in food is control of food temperature. Be sure that food to be served cold is kept cold (below $45^{\circ} \mathrm{F}$.) and food to be served hot is kept hot (above $140^{\circ} \mathrm{F}$.) until consumed. Leftover food should be chilled as rapidly as possible to prevent growth of microorganisms during the cooling process. A third method of preventing staphylococcus food poisoning would be destruction of the staphylococci in the food by heat treating the product after preparation to destroy the organisms. This can be achieved by a pasteurization heat treatment with many liquid products (such as $145^{\circ} \mathrm{F}$. for 30 minutes or $160^{\circ} \mathrm{F}$. for 16 seconds which is used with milk and some 
milk products). Some products such as custard-filled pastries can be heat treated in an oven at 375 to $425^{\circ} \mathrm{F}$. for 30 minutes, or the filling can be heated to $190^{\circ} \mathrm{F}$. for not less than 10 minutes. Of course, if such heat treatments are used, then care should be taken to assure that the food does not become recontaminated after heating.

\section{Ancient Affliction}

It would be extremely difficult to estimate how long food-borne staphylococcus intoxication has afflicted man. Staphylococcus organisms were first identified in 1880 by Pasteur and undoubtedly caused food poisoning for many years prior to their identification. Dr. Dack in his book on food poisoning has a few examples from early literature to illustrate this contention. (2). He points out that as early as 1830 physicians and scientists were aware that certain foods seemed particularly prone to ". . . acquire poisonous qualities of a peculiar kind ..." Sausages and cheeses were often implicated in food poisoning cases in Germany, where both were very popular.

Scientists and physicians also knew that bacon and ham often acquired "... poisonous qualities analogous to those which characterize the sausagepoison and cheese-poison ..."

The theory persisted, however, that such accidents arose from the ". . accidental impregnation of the meat with metallic poisons ..."M. Ollivier published in the Archives Generales de Medicine results of an inquiry into an accident supposedly arising from eating spoiled ham. Although Ollivier was able to repudiate the "metallic impregnation" theory, he could not discover the real cause of the poisoning.

Dr. Dack's book also tells of an instance during this period in which a Parisian purchased a "ham pye" at a pastry-cook's. The man's entire family fell ill the day after eating the meat in the "pye". All members of the family displayed symptoms of staphylococcus food poisoning. The family doctor, however, ascribed the illnesses to ". . . natural verdigris, or the carbonate of copper having been communicated by the pastry-cook's mold ..."

Other outbreaks of this illness occurred among the pastry-cook's customers, and a "judicial investigation" was ordered. However, investigation revealed that the shop's operation was conducted "with due attention to cleanliness."

'In 1879 Henry Leffmann, lecturer in toxicology in the summer school of Jefferson Medical College, called attention to the frequency with which cream puffs had been implicated in outbreaks of food poisoning. He wrote: 'I have made chemical examinations of portions of cream puffs that have caused trouble but have not found anything that could be assigned as the cause of the action'."

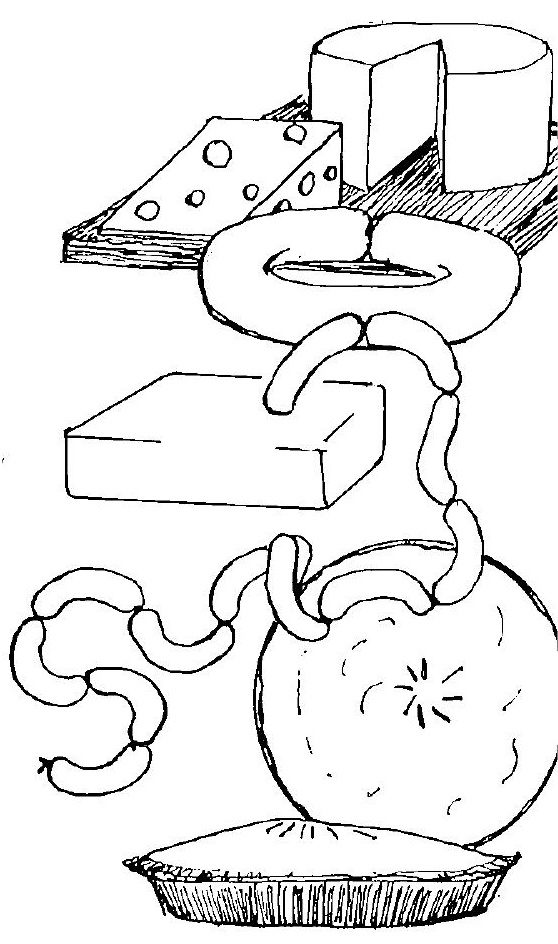




\section{Staphylococcus Aureus Implicated}

In 1884 Professor Victor C. Vaughan first suggested staphylococci as a cause of food poisoning (8) when he clescribed food poisoning outbreaks caused by cheese. He stated, "It is well known that cases of severe illness follow the eating of some kinds of cheese. Indeed such instances have been reported." Professor Vaughan examined some of the cheese from a factory in Michigan and found spherical bacteria. He deducted from his findings that these bacteria were responsible for some chemical change in the cheese that caused the food poisoning.

It was not until 1930 that it was clearly demonstrated by Dr. Dack and his coworkers in Chicago that food poisoning can be caused by the presence and growth of Staphylococcus aureus in food (3). Since their report, the role of staphylococci as a cause of food poisoning has been duly recognized. The long clelay in recognition of staphylococci in food poisoning may be attributed largely to the immense amount of publicity given Salmonella organisms, which is still true today. This delay is also due to the fact that when salmonella were not found, much effort was expended in attempting to find poisonous substances produced by salmonella in the food product.

\section{Reported Outbreaks}

A few examples of recent outbreaks of food-borne staphylococcus intoxication will demonstrate how easily the illness is spread and how simply it can be prevented:

An outbreak of staphylococcus food poisoning occurred recentiy in Texas following a noon meal served to school children at 16 elementary schools. A total of 1,364 children out of the 5,824 that had eaten the lunch became ill. School lunches in this Texas town are prepared in a central kitchen and distributed to the various schools. Food items served at this lunch included chicken salad, lettuce and tomato, french fried potatoes, cupcakes, hot rolls, and milk. Food histories obtained from 95 percent of the children that had eaten the lunch implicated chicken salad as the food responsible for the outbreak.

Preparation of the chicken salad began the afternoon before the lunch. Frozen chickens were boiled for 3 hours. After cooling, the chickens were deboned, cooled with a fan to room temperature, ground into small pieces, placed in 12-inch-deep aluminum pans and stored overnight in a walk-in refrigerator maintained at $42-45^{\circ} \vec{F}$. The following moming the remaining ingredients were added to the chicken and the mixture blended with an electric mixer. The food was placed in themal containers and

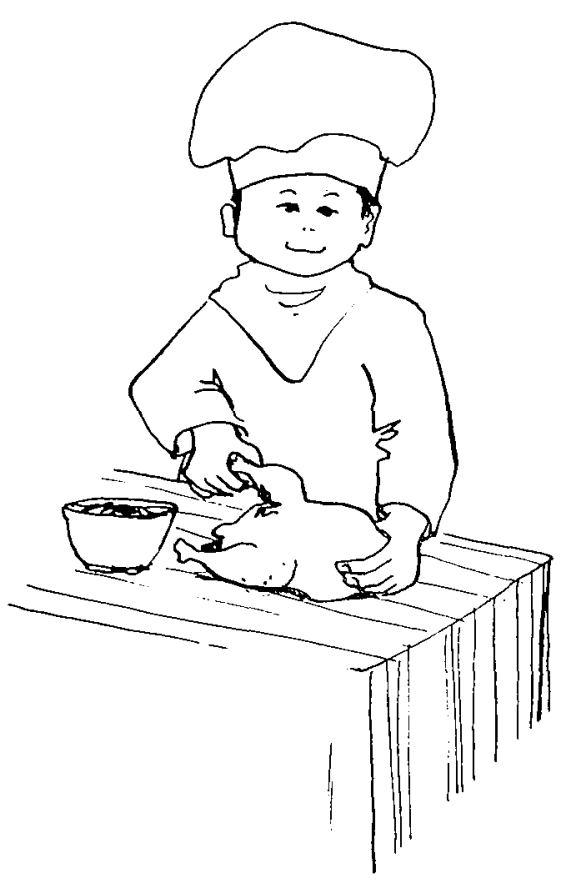




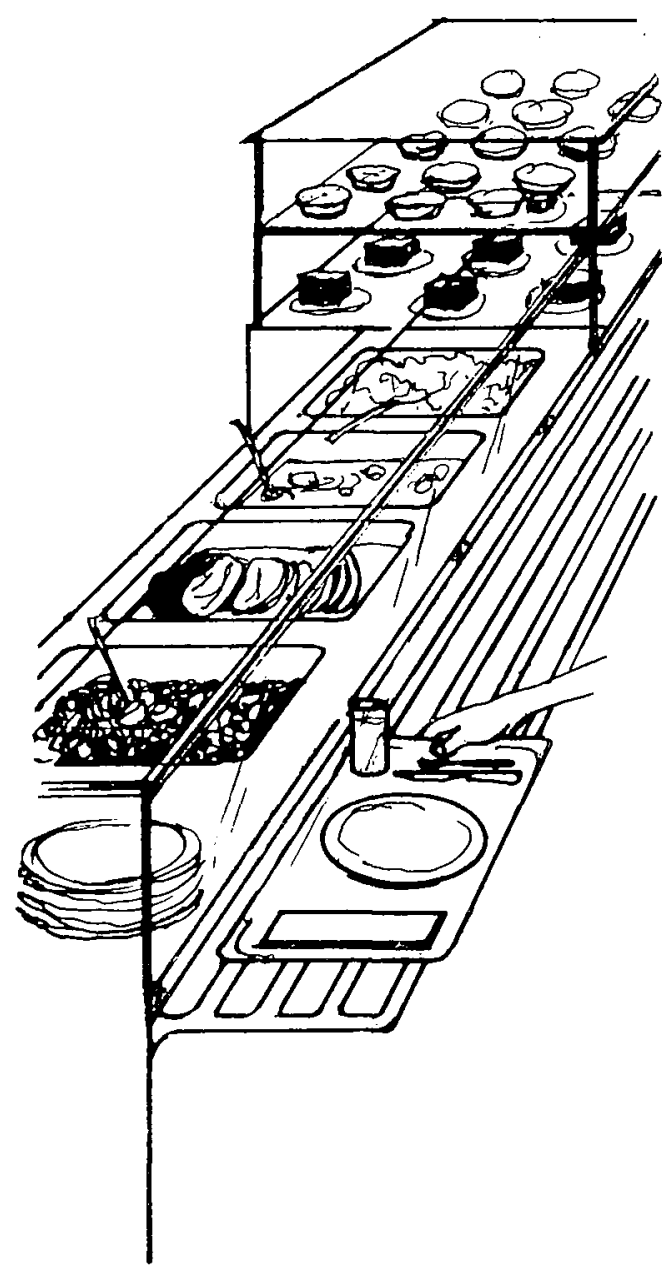

transported to the various schools by truck. None of the schools had facilities for refrigerating food, and the salad was kept at room temperature until served between 11:30 a.m. and noon. At some of the schools the food arrived at 9:15 a.m., while at others it arrived at 10:30 a.m. The schools that received the food earlier had a significantly higher attack rate than those that received the food later.

This particular day was cold and the heating systems in the schools were operating at full capacity. Consequently, the classrooms were quite warm. Several individuals remarked that the rooms where the food had been stored were stuffy, and several teachers commented that the chicken salad was warm when eaten.

Microbiological examination of the chicken salad obtained from the central kitchen showed the presence of Staphylococcus aureus organisms. Nose, throat, and fingernail cultures were taken from the 17 food handlers working in the central kitchen. No boils, pimples, abscesses, or hand or finger lesions were observed in any of the food handlers. One individual was found to contain $S$. aureus in his nose, while two others were found to have $S$, aureus in their throats.

Several factors were responsible for this outbreak of staphylococcus food poisoning. Initial contamination of the chicken occurred when it was cleboned; the chicken was improperly cooled when placed in 12-inch-deep pans allowing growth of the staphylococci to occur in the refrigerator, and the growth continued when the chicken salad was stored in the warm classrooms. This outbreak could have been prevented if the chicken had been properly cooled and kept cold until consumed. For prevention of further outbreaks investigators of this outbreak recommended that food be delivered from the central kitchen to the schools as close to mealtime as possible. They further suggested that refrigeration facilities be installed in the schools and that deep pans for the refrigerated storage of warm foods be eliminated (6).

Several hours after eating a noon meal, 17 persons aboard a ship became ill. Nausea, vomiting, cramps, and diarrhea were the symptoms. Macaroni salad served at the meal was found to contain Staphylococcus aureus microorganisms. The ingredients of the salad had been hand-mixed by two of the cooks. One of the cooks had several minor cuts on two fingers. These finger cuts yielded $S$. aureus, the same type of bacteria found in the salad (7). This outbreak could have been prevented quite simply. Never use hands to mix foods when clean sanitized utensils are available. Never work with food when you have an infected cut because the bacteria causing the infection may be a source of food-borne disease!

Leftover food contaminated with $S$. aureus from unclean equipment and food handlers was responsible for several outbreaks of food-borne staphylococcus intoxication at a private school in New Hampshire (5). The largest outbreak involved a banquet served to approximately 180 persons. Samples of the food served were obtained and cxamined bacteriologically. The roast beef served at the banquet was found to be heavily 
contaminated with staphylococci. This same meat was served 2 days later at another meal and a second attack of food poisoning occurred. Examination of the food preparation area indicated it was tidy and well kept. Six of seven kitchen employees were found to harbour staphylococci in their nose and/or throat and intestinal tract. Bacteriological examination of the kitchen environment revealed that the meat slicer and meat block were heavily contaminated with Staphylococcus aureus. Inspection of the walkin refrigerator revealed many items of leftover food. Apparently the chef was reluctant to discard leftover food and preferred to keep it to serve again at future meals.

These recurring outbreaks of staphylococcus food poisoning were eliminated at this school after preventive measures were instituted. These included cleaning and sanitizing all kitchen utensils and work surfaces, proper handling and refrigeration of cooked foods, discarding of leftover food not to be used quickly, and treatment of the food handlers with antibiotics to eliminate the staphylococci in their systems.

This study is particularly interesting because of the repeated outbreaks of food poisoning traceable not to the usual boils or other infected skin lesions of humans, but to food poisoning staphylococci shed from the noses, throats, and gastrointestinal tracts of the food handlers.

The account of an outbreak of food-borne staphylococcus intoxication used to illustrate factors necessary to cause an outbreak discussed earlier in the bulletin is based on an actual outbreak that occurred at a picnic in Ohio. Of the 306 persons attending the outing 244 became ill. The food found to be the cause of the outbreak was ham. It had been contaminated by a catering firm employee afflicted with acne. This particular employee had the unconscious habit of fingering and squeezing these facial infections and had done so while slicing the ham and unknowingly inoculated the ham with Staphylococcus aureus! The ham was subsequently wrapped tightly in foil and kept warm for several hours before consumption. All the conditions were provided for the development of an outberak and subsequently one did occur (9).

In each of the examples of staphylococcus food poisoning cited, the source of the causative organisms was different, yet in each the organism gained entrance into the food, the food was mishandled allowing the bacteria to grow and produce enterotoxin, and an outbreak of food poisoning resulted.

These examples illustrate how cleanliness and good, sound food handling practices can help prevent staphylococcus food poisoning
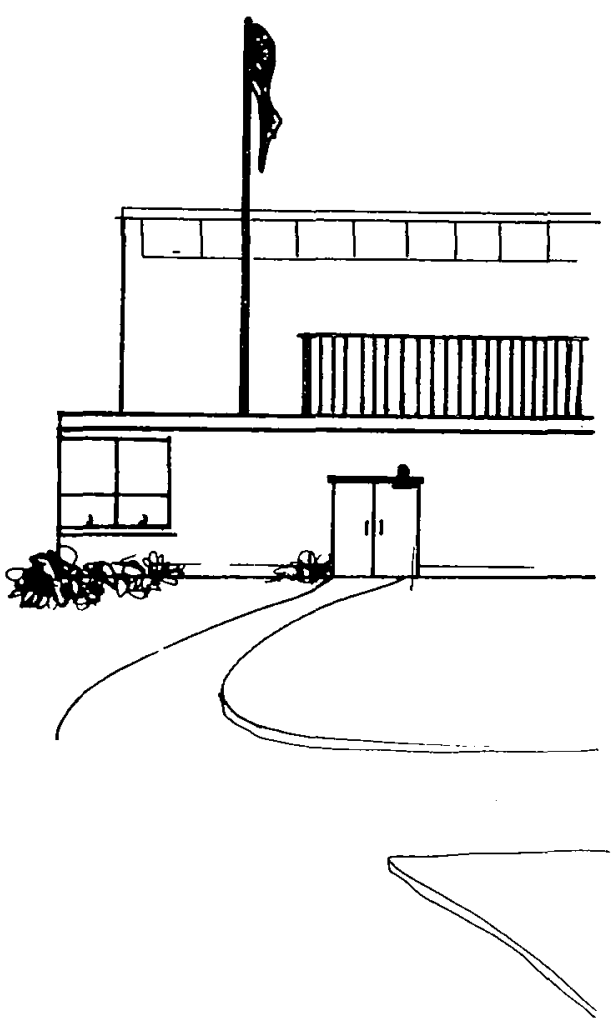


\section{Precautions for Prevention}

Elimination of outbreaks of Staphylococcus food poisoning requires constant attention to correct food handling practices and an awareness of the problem and methods of prevention. The following general practices should be observed when handling food to prevent contamination and subsequent growth of Staphylococcus aureus in the food:

\section{Good Sanitation Practices}

Individuals handling food either at home or in a food processing plant should observe good sanitation practices to minimize opportunities for contamination. All buildings, equipment, and utensils used for processing food should be designed and constructed so that thorough cleaning is easy and practical. Processing plant personnel should be encouraged to practice sound personal hygiene and to report any illness, skin infection, rash, or boils.

Food handlers should be encouraged to wear plastic or rubber gloves that can be cleaned and sanitized frequently. Every effort should be made to prevent contamination of the food with staphylococci.

Those handling prepared food should:

1. Always work with clean hands. Never use your hands to mix food when clean, sanitized utensils are available.

2. Always wash hands thoroughly after going to the toilet or handling raw food.

3. Wear clean and sanitary plastic or rubber gloves whenever possible, particularly if there is a cut or skin irritation on the hands.

4. Keep hands away from mouth, nose, hair, and skin infections.

5. Cover coughs and sneezes with tissue.

6. Don't use cooking utensils or fingers to taste food while cooking or serving; don't lick fingers or eat while preparing food.

7. Kitchen equipment should be well scrubbed to prevent cross-contamination between raw and cooked foods.

\section{Low Temperature Storage}

Storing food at low temperatures by freezing or refrigeration is an effective preventive to staphylococci growth. However, this does not destroy the organism, and once the food is placed in a more favorable temperature, growth can occur. Prepared food not to be consumed immediately should be refrigerated as quickly as possible so that the center of the food reaches $50^{\circ} \mathrm{F}$. within a short time. Be sure that food to be served cold is kept cold, below $45^{\circ} \mathrm{F}$. until consumed.

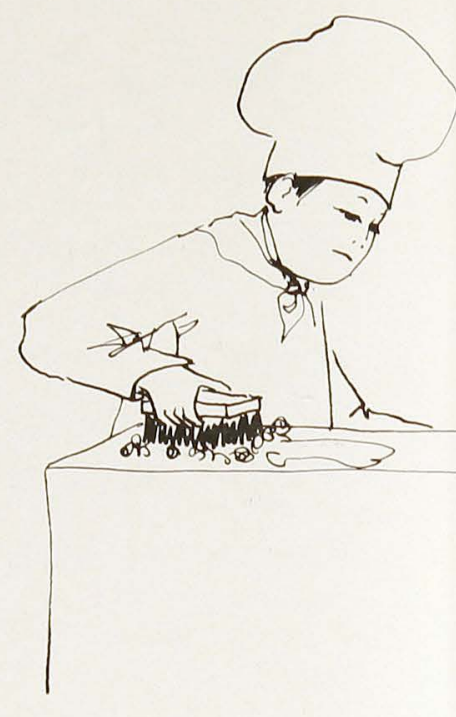

Temperature Guide

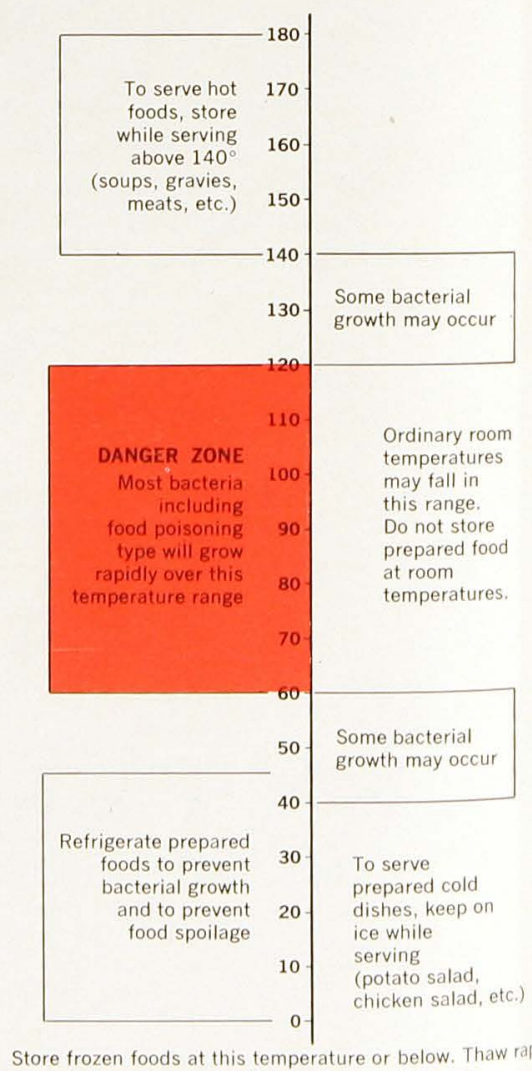
Store frozen foods at this temperature or below. Thaw
or cook from frozen condition when ready to use, 


\section{Adequate Cooking}

Heat will destroy staphylococci. Adequate cooking will assure destruction of these organisms. But regardless to what temperature the food is heated, recontamination of the food after heat treatment often occurs and should be prevented. Heat treatment will not destroy any enterotoxin present in the food before cooking. Since no detectable change in the food is produced by these bacteria when growing and producing toxin, it is essential that food be handled properly before cooking as well as after. A good motto to follow is "When in doubt - throw it out."

\section{Danger Zone}

Storing prepared food at temperatures that enhance the growth of staphylococci should be avoided. When food is exposed to temperatures between $50^{\circ} \mathrm{F}$. and $110^{\circ} \mathrm{F}$., holding time should be kept to a minimum (see temperature guide). All foods should be refrigerated promptly after a meal or cooking and should be stored at a temperature below $45^{\circ} \mathrm{F}$.

The prevention of outbreaks of food-borne staphylococcus intoxication requires diligent attention to details of sanitation, food handling practices, and temperature control. Only through the concentrated efforts of all individuals involved can an unpleasant experience at a social gathering or family dinner be prevented.

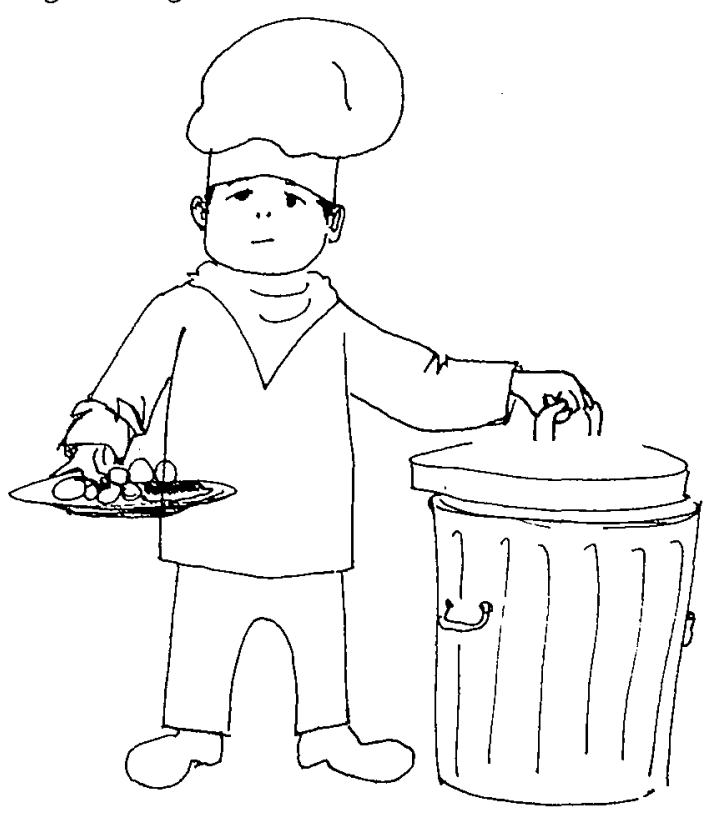

"When in doubt, throw it out!" 


\section{REFERENCES}

1. Dack, G. M. 1962. Staphylococcal Enterotoxin. Chemical and Biological Hazards in Food. Edited by J. C. Ayres, A. A. Kraft, H. E. Snyder, and H. W. Walker, Iowa State Univ. Press, Ames, Ia.

2. Dack, G. M. 1956. Food Poisoning. Univ. of Chicago Press, Chicago, Ill.

3. Dack, G. M., O. Woolput, I. Noble, and E. C. Holliday. 1931. "Experimental Study of Possible Routes of Contamination of Cakes with Food Poisoning Staphylococci." J. Preventive Medicine 5:391.

4. Frazier, W. C. Food Microbiology. 1967. Second Edition. McGrawHill Book Co. New York.

5. Prince, William and G. K. Crowell. 1950. "Identification of Staphylococcus aureus in a Food Poisoning Incident." Public Health Reports $75: 11: 1067$.

6. U.S. Dept. of Health, Education and Welfare. 1968. Morbidity and Mortality Weekly Report. March 30. 17:13:109.

7. U.S. Dept. of Health, Education and Welfare. 1963. Public Health Service Publication No. 1105.

8. Vaughan, A. C. "Poisonous or Sick Cheese." 1884. Public Health Papers and Reports. American Public Health Assn. 10:241.

9. Wain, Harry and P. A. Blackstone. 1956. "Staphylococcal Gastroenteritis - Report of a Major Outbreak." Amer. J. Digestive Diseases $1: 10: 424$

10. Wilson, G. S. and A. A. Miles. 1964. Topley's and Wilson's Principles of Bacteriology and Immunity. Vol. II. The Williams and Wilkins Co., Baltimore.

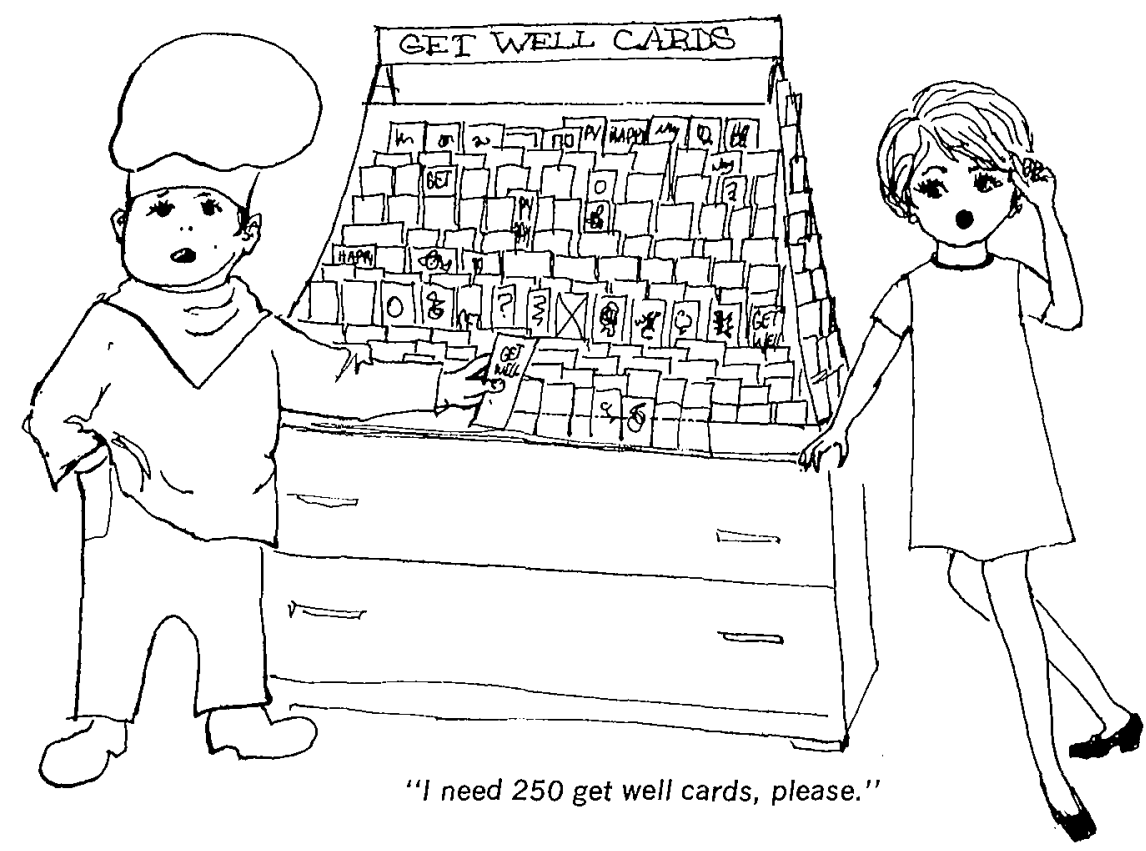


Edmund A. Zottola is associate professor, Department of Food Science and Industries, and extension food microbiologist.

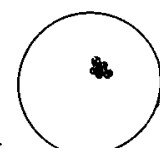

Issued in furtherance of cooperative extension work in agriculture and home economics, acts of May 8 and June 30, 1914, in cooperation with the U.S. Department of Agriculturc. Roland H. Abraham, Director of Agricultural Extension Service, University of Minnesota, St. Paul, Minnesota 55101. 